\title{
Friction coefficient and wear resistance of a modified polypropylene impregnated with different oils
}

\author{
P. Sędłak ${ }^{1}$ B. Białobrzeska ${ }^{2}$ T. Stawicki ${ }^{1}$
}

Received: 19 June 2015 / Accepted: 27 January 2016 / Published online: 9 February 2016

(C) The Author(s) 2016. This article is published with open access at Springerlink.com

\begin{abstract}
The aim of the study was to determine the changes in the sliding friction coefficient and wear mechanism of PP impregnated by oils with respect to the unmodified PP under dry sliding conditions. The study showed that the impregnation of the PP clearly influenced the wear rate of PP and its friction coefficient. During the test, the wear behavior of the unmodified and impregnated polypropylenes was investigated using ASTM G77-98 standard wear test equipment in which the specimens were worn by counter sample made by steel $100 \mathrm{Cr} 6$. The recording program of the test system enabled the visualization and registration of the following parameters: specimen rotation and load value, linear wear of specimen, friction coefficient, and temperature of specimen and environment. The wear of the specimens was evaluated by weight loss and their wear mechanisms were investigated using scanning electron microscopy. The predominant wear mechanism between a polymer and steel was adhesion. However, at the high sliding velocity, when a higher temperature was generated, the predominant mechanism of wear was thermal wear. Impregnation of PPs moved the thermal wear into the higher sliding velocity values and caused better resistance of the PPs to melting and plastic flow. The most important finding of this investigation was that impregnation of PPs improved their tribological properties at a low value of load represented by the sliding velocity.
\end{abstract}

B. Białobrzeska

beata.bialobrzeska@pwr.edu.pl

1 Department of Agrotechnical Systems Engineering, West Pomeranian University of Technology, Papieza Pawla VI Street 1, 71-459 Szczecin, Poland

2 Department of Materials Science, Welding and Strength of Materials, Wroclaw University of Technology, Smoluchowskiego Street 25, 50-370 Wrocław, Poland
Keywords Polypropylene - Two-body wear test . Adhesion $\cdot$ Thermal wear $\cdot$ Impregnation

\section{Introduction}

In the construction and exploitation of machine components, special consideration is given to the application of fundamental knowledge about wear behaviour through lubrication. This problem has become more significant because one of the consequences of the development of technology is that the values of dynamic and temperature loads transmitted by friction pairs have increased. Sliding pairs, which constitute the moving cells of most machinery, have a major impact on the durability and operational reliability of the entire machine. For proper operation of the machine elements sliding over each other, an important role is played by the selection of materials that work together during sliding. Most often one element of the sliding pair is made of modified steel, while the material of the second element is selected for its anti-frictional properties during cooperation (the lowest coefficient of friction and the lowest wear during its work).

Bushings of the plain bearings, carrying the heavy loads, are made of special bearing alloys that are characterized by a low friction coefficient and high strength. However, they require proper and continuous lubrication to reduce wear and to increase durability and reliability. The construction of lubrication systems and the need for continuous supervision increase the cost of the making of the device and the cost of its further exploitation. Besides bearing alloys for the construction of slide bearings, sintered metal powders and their alloys are also used. Thereby, a porous structure that can be impregnated by grease agents or nanomaterials 
is achieved, which enables the construction of self-lubricating and maintenance-free bearings [1].

However, in many machines used in agriculture, the food industry, robotics engineering, home appliances, and the textile industry, where the sliding loads of bearing nodes are much lower, the guide and the plain bearing elements are often made of polymers and their composites. Polymers such as polytetrafluoroethylene (PTFE), fluorinated ethylene propylene (FEP), polyamides (PA), polyethylenes (PE), polyacetals (POM), polyimides (PI), polyether ether ketone (PEEK), and polypropylene (PP) are most frequently used as bearing materials in such systems [2-4].

In many friction pairs, the sliding surface of the polymers usually matches a partner surface made of steel or other hard metals. As reported by Stachowiak et al. [5], polymers are known to be more effective, with regard to friction and wear resistance, against a metal than when sliding against themselves.

Polymers are used mainly where it is difficult or even impossible for lubrication to be performed by conventional methods, and bearings made of polymers exhibit the features of maintenance-free bearings. In most cases of bearing systems based on polymers, there is no need for additional lubrication and the friction process takes place in dry friction conditions [6-8]. The use of polymer as a construction material for maintenance-free bearings is dictated by several advantages, such as low energy losses due to the low coefficient of dry friction, self-lubricating ability, ability to absorb hard particles, self-lapping ability, low abrasive wear, reduction of vibration, water and grease resistance, lightness, flexibility, and workability. Under some conditions of friction, polymeric materials achieve a higher wear resistance than steel, for example [9].

It should be added that in order to improve the cooperation of polymers in a friction pair an attempt was made to use liquid and plastic grease lubrications, which resulted in their wear reduction significantly [10]. However, in this case, the primary advantage of polymer bearings, namely their maintenance-free feature, is lost.

The major factors defining the capability of polymers to be used as the construction material of sliding elements cooperating with elements made of steel are the pressure exerted on the bearing, the rotational velocity and consequently the linear velocity, and the friction coefficient, which affects the heat generation due to friction work. The low thermal conductivity of the polymers also affects the application of these materials for the construction of slide assembly, due to the accumulation of heat in the friction zone and thus lower wear resistance. Therefore, they have been applied in friction pairs with low line velocity and low loads. The negative impact of low thermal conductivity and relatively low mechanical strength of the polymers can be reduced, to some extent, by modifying these materials. The most commonly used modifiers are powdered metals or their alloys (tin, lead, copper bearing alloys, oxides of some metals) and powdered non-metallic additives (graphite, carbon black, molybdenum disulfide, chalk, and other polymers). Additives may also be added in the form of carbon, steel, glass fibres, or fibres made of other polymers. These additives thereby form a composite polymer [11], allowing the tribological and strength properties of the polymers to be improved. Another way to modify the physical and mechanical characteristics of the polymers is by impregnating them with lubricating agents as in the case of bearings made of sintered powders. However, different methods of modifying polymers do not significantly increase the thermal conductivity of the material. Thus, even guide and sliding bearing elements made of modified polymers cannot operate at very high line velocity and loads.

The selection of the polymers for the friction pair should be based on an evaluation of their performance in the context of given requirements. The evaluation of the functional features of the polymers is made on the basis of parameters describing their properties, such as the value of the coefficient of friction, the wear rate, the permissible operating temperature, and chemical resistance to materials with which they make contact. A major problem in the selection of the polymer is to determine the type of wear to which it will be subjected during operation, because depending on the type of material and loads, the wear process may occur in different ways [12, 13].

The wear rate depends strongly on the predominant mechanism of wear. Studies of the sliding behaviour of polymers have been taking place for more than 50 years and several models of friction have been proposed as a result [17]. The friction theory of polymers is based on the concept of friction duality: deformation and adhesion [14]. Quaglini and Dubini reported that the two main mechanisms of friction between a polymer pad and a metal surface can be considered to be predominant: "the shearing of the junctions formed by adhesion between the asperities of the contacting surfaces, and the dissipation of energy due to plastic deformation and abrasion $[5,15,16]$ under high contact stresses the asperities of the harder material ploughs the softer one, and the resistance to ploughing further contributes to increase the frictional force" [17]. In recent years the adhesion theory of Bowden and Tabor [15] has been most significant, especially when it was supported by experimental evidence. Models of contact with adhesion are the Johnson-Kendall-Roberts Model (which assumes that interactions occur only within the contact area) [14] and the Deryaguin-Muller-Toporov Model, which solves the problem of the effect of elastic contact deformation on adhesion [14]. The main factor that initiates a sharp decrease in the adhesion is roughness. Basic elements to be considered regarding the friction of polymers are the real 
Table 1 Selected physical properties of the unmodified polypropylene under study [19]

\begin{tabular}{ll}
\hline Density & $0.91 \mathrm{~g} \mathrm{~cm}^{-3}$ \\
Tensile strength & $35 \mathrm{~N} \mathrm{~mm}^{-2}$ \\
Elongation-at-break & $700 \%$ \\
Tensile modulus & $1300 \mathrm{~N} \mathrm{~mm}^{-2}$ \\
Hardness & $75 \mathrm{~N} \mathrm{~mm}^{-2}$ \\
Operating temperature range & \\
For short-term operation & $140{ }^{\circ} \mathrm{C}$ \\
For continuous operation & $100{ }^{\circ} \mathrm{C}$ \\
Thermal conductivity & $0.22 \mathrm{~W} \mathrm{~K}-1 \mathrm{~m}^{-1}$ \\
Melting point & $165{ }^{\circ} \mathrm{C}$ \\
Humidity absorption saturation at $23{ }^{\circ} \mathrm{C}$ & $0.03 \%$ \\
Water absorption saturation & $0.1 \%$ \\
\hline
\end{tabular}

contact area and the type and strength of interfacial bonds. Both theoretical and experimental studies have concluded that the real area of contact is almost linearly proportional to the load. Another factor that could have a considerable influence on the contact area is the temperature, which in turn is strongly dependent on the load [14]. Moreover, the mechanical properties of polymers are sensitive to changes in temperature and liable to chain degradation from exposure to heat.

A special polymer whose properties can be highly modified to meet specific requirements [18] is polypropylene (PP). PP is a polymer from the group of polyolefins that is obtained by low-pressure polymerization of propylene [14]. One of its main features is its outstanding versatility. The structural features (inexpensive material, with relatively good performance in terms of strength and easy processability) of PP and the possibility of designing its properties provide a wide variety of tribological applications. This initiated the research focused on the tribological behaviour of this material [14, 18].

Although some research has been conducted and various test methods and equipment have been used to evaluate the resistance to sliding wear of the PPs, research on their wear resistance in dry sliding conditions still needs to be developed. The aim of this study was to determine the changes in the sliding friction coefficient and wear mechanism of PP modified by impregnating oils with respect to the unmodified PP under dry sliding conditions.

\section{Experimental}

\section{Materials}

For the laboratory two-body wear test, samples made from unmodified and modified PP were used. Modification of PP
Table 2 Averages values of Shore hardness of tested specimens

\begin{tabular}{lllll}
\hline & $\begin{array}{l}\text { Unmodified } \\
\text { PP }\end{array}$ & $\begin{array}{l}\text { PP impreg- } \\
\text { nated with } \\
\text { rapeseed oil }\end{array}$ & $\begin{array}{l}\text { PP impreg- } \\
\text { nated with } \\
\text { gear oil }\end{array}$ & $\begin{array}{l}\text { PP impreg- } \\
\text { nated with } \\
\text { motor oil }\end{array}$ \\
\hline${ }^{\circ}$ Sh) & $\begin{array}{l}72.2 \\
\end{array}=0.3$ & $\begin{array}{l}59.5 \\
s=1.1\end{array}$ & $\begin{array}{l}62.4 \\
s=0.5\end{array}$ & $\begin{array}{l}64.6 \\
\end{array}$ \\
\hline
\end{tabular}

consisted of impregnating it with three sorts of oils. The bearing steel 100Cr6 was used as a counter sample.

The physical properties of the investigated PP are summarized in Table 1.

Samples were made from a rod with a diameter $10.5 \mathrm{~mm}$. The rod was cut into sections with lengths of $19 \mathrm{~mm}$, then shortened to a length of $17 \mathrm{~mm}$ using a lathe, and chamfered. After cleaning using technical acetone and benzine, samples were weighed on a WPS510/C/1 analytical scale. The accuracy of the weight was $\pm 0.001 \mathrm{~g}$. The diameter of the samples was measured using a minimeter with an accuracy of $0.001 \mathrm{~mm}$.

PP was subjected to modification using a vegetable oil, namely rapeseed methyl ester (RME) oil, and two mineral oils, namely Hipol GL 480 W/90 gear oil [20] and HD Diesel Formuła 15 W/40 motor oil [21] that were made in Poland. The modification process consisted of impregnating the samples by immersing them in the oils heated to a temperature of $105{ }^{\circ} \mathrm{C}$ for $24 \mathrm{~h}$. After the impregnation process, the samples were cleaned, reweighed, and measured. After an additional $24 \mathrm{~h}$ the samples were cleaned for a second time, measured, and weighed again in order to determine whether there had been any change in the amount of absorbed oil and in the stabilization of the dimensions of the samples. Depending on the type of oil, different degrees of impregnation of the samples were obtained (measured as the change of weight after impregnation with respect to the weight before impregnation). The degree of impregnation with RME oil was 15-17 \%, with Hipol it was 7-9 \%, and with motor oil it was 9-11\%.

The average values of Shore hardness of the tested specimens are presented in Table 2. The hardness measurements were performed using a Shore hardness tester type D.

As a counter sample, already mentioned, 100Cr6 bearing steel was used, from which a ring with a diameter of $35 \mathrm{~mm}$ and width of $8 \mathrm{~mm}$ was made. The ring was quenched and tempered. Its hardness after heat treatment was 48 HRC. The surface that cooperated with the sample was subjected to a grinding process so that the obtained surface roughness was $0.29 \mu \mathrm{m}$.

\section{Methods}

The study on the change of the frictional moment was performed using a tribometer made by the Department of 


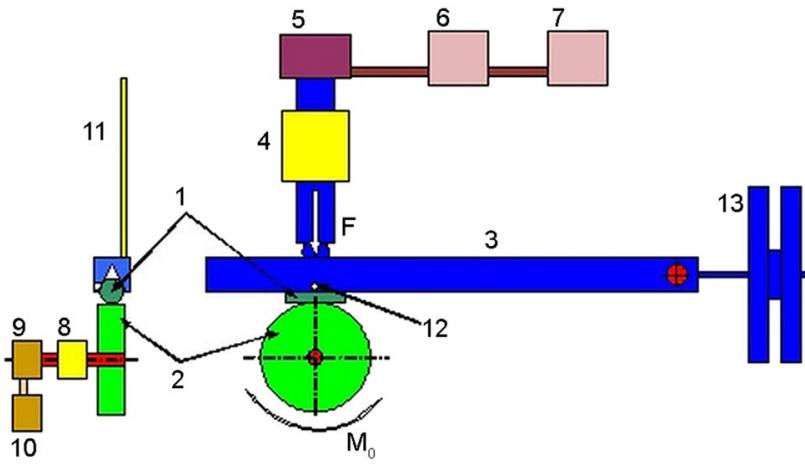

Fig. 1 Scheme of the test equipment: 1 tested sample; 2 counter sample; 3 sample holder; 4 force sensor; 5 pneumatic actuator; 6 pressure controller; 7 compressor; 8 torque sensor; 9 electric motor; 10 frequency converter; 11 displacement sensor; 12 thermocouple; 13 counterweight

Agrotechnical Systems Engineering of the West Pomeranian University of Technology located in Szczecin in Poland [22]. The scheme of the test equipment is shown in Fig. 1. The basic test machine consisted of a Freqvar 3000 frequency converter (11) that controlled the electric motor (10). The electric motor was connected by a torque sensor (9) with a counter specimen (2). The load was generated by an Agromech-Mogilno FMP pneumatic actuator (5), which cooperated with the compressor (8), A201-A 101 D2 pneumatic converter (6), and AW 3000-03 pressure controller (7). A counter-weight (14) was used to eliminate the impact of the mass of the holder (3) on the specimen. The load value of the tribological pair was controlled by the force sensor (4) placed between the pneumatic actuator and the sample holder (3). Measurement of the specimen displacement with respect to the counter specimen was carried out via an LVDT5 type inductive displacement sensor (12). This made it possible to measure the wear of the sample to the nearest $0.001 \mathrm{~mm}$. The test device was also equipped with two TP-202 class $\mathrm{K}$ thermocouples, with which the temperature of the sample and the environment was measured. It should be noted that the thermocouple (13) was only able to measure the overall temperature of the sample but could not directly measure the temperature of the friction surface.

The work of the tribometer was controlled by an MW-5 interface cooperating with software installed on a PC. To determine the parameters of the tribometer, STEDIT 101 software was used, where the load value, load duration, rotation speed of the counter specimen, and direction of rotation of the counter specimen were programmed. The recording program enabled the visualization and registration of the following parameters: specimen rotation and load value, linear wear of specimen, friction coefficient, and temperature of specimen and environment. The preparation of the test stand and initiation of the research were carried out in accordance with the ASTM G77 standard [23] each time. The counter specimen was cleaned using sandpaper with a granularity of 600 and then defatted together with the tested sample. The samples were reweighed, fixed in the tribometer holder, and loaded and the test was run. Each run started with an initial lapping of friction elements with constant rotation speed, constant friction road (184 m), and a constant load $(100 \mathrm{~N})$. The parameter values recorded by the measuring system during initial lapping were not taken into consideration during the analysis of the results.

The research was carried out at given linear velocities of the sample surface, namely $0.13,0.26,0.44,0.62$, 0.80 , and $1.00 \mathrm{~m} \mathrm{~s}^{-1}$. The lowest value was due to technical capabilities of the test equipment. At a velocity value of about $1 \mathrm{~m} \mathrm{~s}^{-1}$, classic bearings can be used because a lubricant gap has already formed at this velocity value. In the research, for each variant of tribological pair and conditions of its work, constant values of sliding distance and load amounting to $1840 \mathrm{~m}$ and $343 \mathrm{~N}$, respectively, were assumed. The value of the loading force was due to the limit of the surface pressure for PP. However, in the preliminary study carried out for $240 \mathrm{~min}$, it was found that the stabilization of the operation parameters of friction took place significantly earlier. A sliding distance amounting to $1840 \mathrm{~m}$ corresponded to the lowest sliding velocity value of $0.13 \mathrm{~m} \mathrm{~s}^{-1}$ and time of $240 \mathrm{~min}$. The same sliding distance was assumed for the other sliding velocity values.

After the wear test, the specimens were reweighed in order to determine their mass wear.

It should be noted that for each combination of a tribological pair and a sliding velocity value, seven repetitions of the measurements were performed with the aim of determining the research parameters.

\section{Results and discussion}

\section{Friction coefficient}

Figure 2 presents representative curves of friction coefficient for unmodified and modified PP tested at room temperature at sliding velocities of $0.13,0.26,0.62,0.80$, and $1.00 \mathrm{~m} \mathrm{~s}^{-1}$. In addition, Fig. 3 shows the average maximum value of friction coefficient. The friction coefficient curve is very important for characterizing the process variation of friction materials. It should be noted that the sliding velocity also affects the coefficient of friction through its effect on the frictional heating. For low values of sliding velocity, impregnated PP shows an improvement in comparison to unmodified PP (Fig. 3).

In the case of a sliding velocity of $0.13 \mathrm{~m} \mathrm{~s}^{-1}$, the unmodified specimen exhibits a slight increase in the value 
(a)

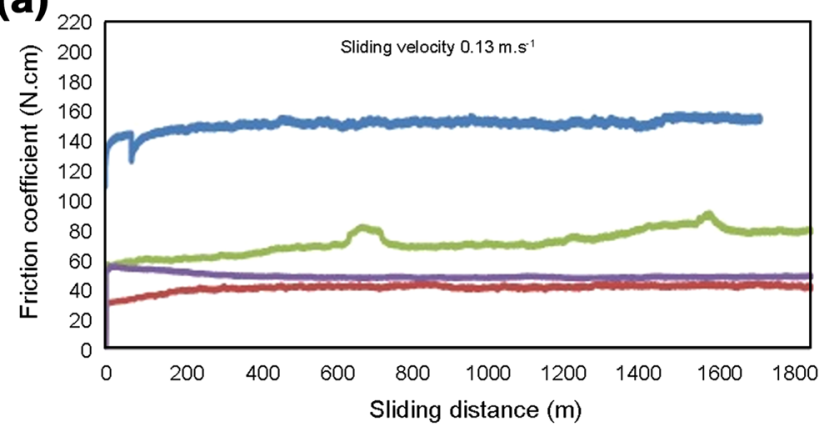

(c)

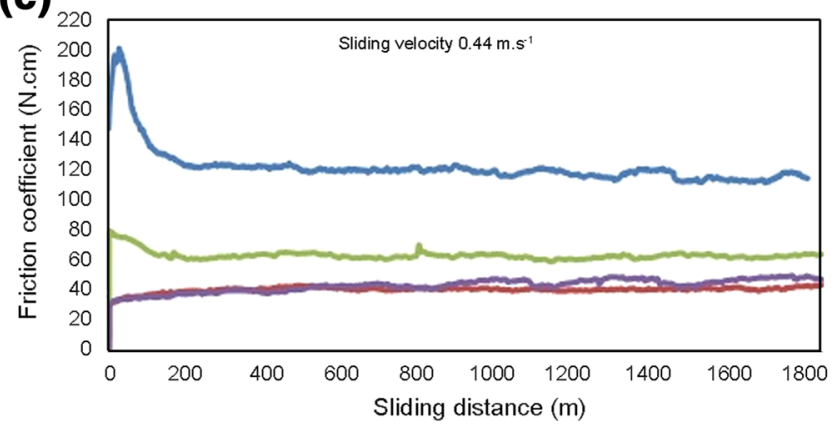

(e)

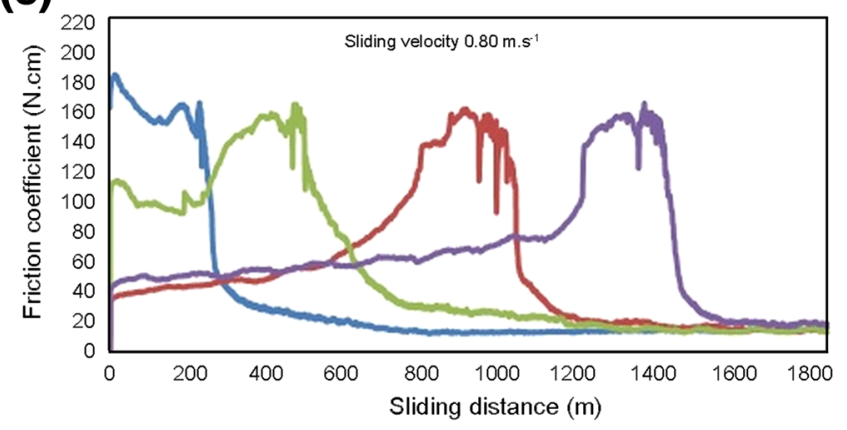

(b)

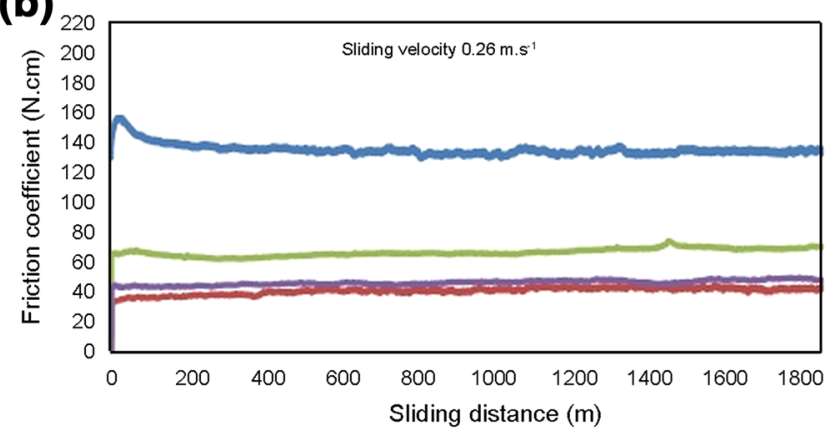

(d)

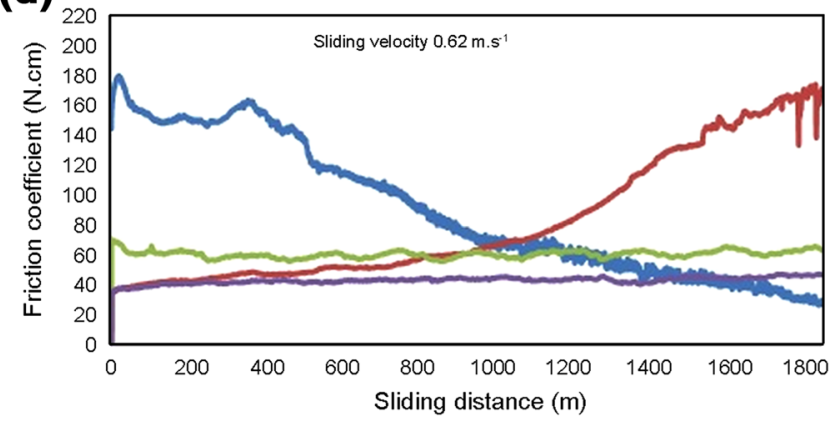

(f)

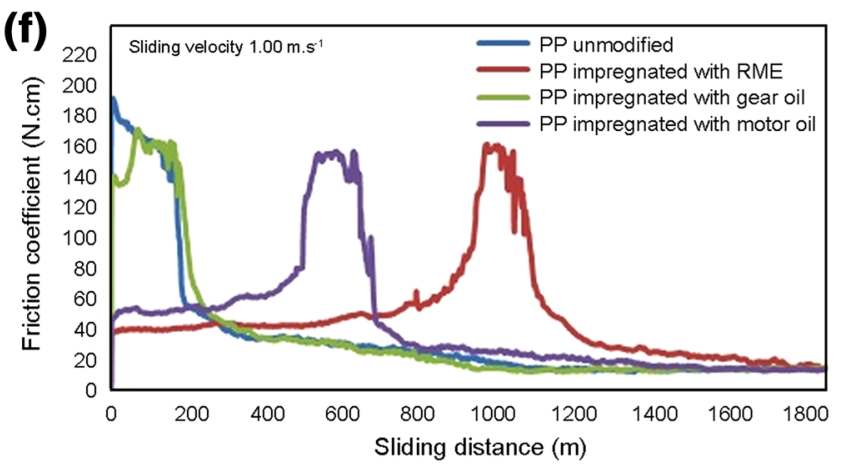

Fig. 2 Relationship between the sliding distance and the friction torque of the sample under different sliding velocity values

Fig. 3 Effect of sliding velocity value on average maximum value of friction coefficient

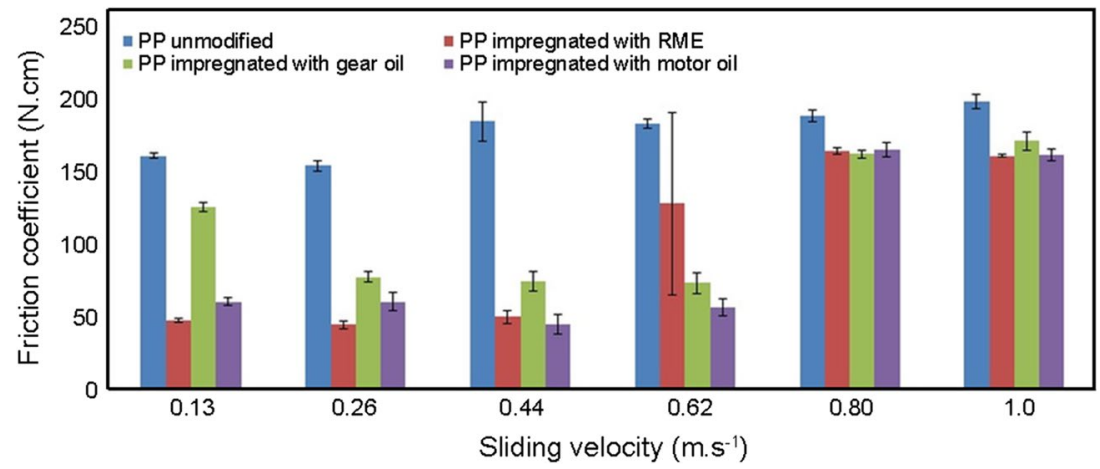

been shown by the specimens made of impregnated PP. By introducing impregnation with RME and motor oils, significant changes in the evolution of friction curves could be observed. The lowest value was noted for PP impregnated of friction coefficient (with a minimum at sliding distance of about $125 \mathrm{~m}$ ) (Fig. 2a). Its value of friction coefficient is also the highest in comparison to modified PP specimens. Significantly low values of friction coefficient have 
with RME oil, but for the specimen impregnated with motor oil, the friction coefficient was not much higher. The reduction in value of the maximum friction coefficient was $70 \%$ in the case of PP impregnated with RME and $62 \%$ in the case of PP impregnated with motor oil (Fig. 3) in comparison to unmodified PP. An interesting situation was noticed for PP modified with gear oil. Its friction coefficient rises slightly and shows two maxima after distances of 678 and $1578 \mathrm{~m}$. Even when the sliding velocity rises twofold to the value of $0.26 \mathrm{~m} \mathrm{~s}^{-1}$, the curves of all samples evolve similarly (Fig. 2b) like the curves noted for the lower sliding velocity value. A slight difference was noted only in the shape of the curve of the unmodified PP. While the curve rises slightly at a sliding velocity of $0.13 \mathrm{~m} \mathrm{~s}^{-1}$, at a sliding velocity of $0.26 \mathrm{~m} \mathrm{~s}^{-1}$ it drops slightly with a maximum after a sliding distance of $152 \mathrm{~m}$. PP impregnated with RME shows a $71 \%$ lower value of maximum friction coefficient in comparison with unmodified PP when PP is impregnated with gear and motor oils: 49 and $57 \%$, respectively (Fig. 3).

A very different character of transition of friction coefficient curves was noted for a sliding velocity of $0.44 \mathrm{~m} \mathrm{~s}^{-1}$ (Fig. 2c). The highest value of friction coefficient was still observed for unmodified PP. The maximum value was noted after a sliding distance of $200 \mathrm{~m}$. After that the friction coefficient drops rapidly to a value of about $200 \mathrm{Ncm}$. It should be added that the variation in the friction coefficient was very small in the case of impregnated PP, indicating excellent friction stability. The lowest values and best stability of the friction coefficient parameters were observed for PP impregnated with RME and motor oils. A significant reduction in the value of maximum friction coefficient is still visible: PP impregnated with RME shows a reduction of $73 \%$, PP impregnated with motor oil, $76 \%$, and PP impregnated with gear oil, $60 \%$ (Fig. 3).

For a sliding velocity of $0.62 \mathrm{~m} \mathrm{~s}^{-1}$, the shape of the curve changes dramatically for unmodified PP and PP impregnated with rapeseed oil (Fig. 2d). The friction coefficient of PP impregnated with RME oil increases and finally shows the typical "rooster tail" feature which might cause the vibration. A totally opposite shape of the curve was observed for unmodified PP. The decrease in frictional coefficient value can be explained by the Bekhet and Naga theory [23]; that is, the friction force between a thermoplastic and a steel surface decreases during the sliding due to the increasing molecular orientation of the thermoplastic parallel to the sliding direction. In the case of the sample of PP impregnated with gear and motor oils, the variation in friction coefficient is still very small. The value of friction coefficient for these specimens is similar to that for the lower value of sliding velocity. Modified PP still shows an improvement in the average value of maximum friction coefficient in comparison to unmodified PP (the reduction in the average value of maximum friction coefficient was 30,69 , and $60 \%$ in the cases of PP impregnated with RME, motor, and gear oils, respectively) (Fig. 3). For the higher values of sliding velocity (Fig. 2e, f), friction coefficient curves change significantly. For modified PP specimens, with increases in distance, the friction coefficient first increases slowly, then increases rapidly, and finally drops and stabilizes. However in the case of unmodified PP the value of friction coefficient is high from the beginning of the test and then after a distance of $300 \mathrm{~m}$ it stabilizes and finally drops dramatically. This stabilization may be due to the fact that during the test at the highest value of velocity the plasticization (liquefaction) of materials takes place. A characteristic feature of PP is its low thermal conductivity. Frictional heat temperatures can easily reach the melting point of the polymer and cause its surface to melt. When the polymer melts, its friction tends to decrease, according to a mechanism of thermal control of friction [24]. With decreasing friction coefficient, the wear of PP (Fig. 4a) also decreases. The linear wear rises rapidly and after achieving a maximum value does not proceed. The sliding distance travelled, when the maximum value of linear wear is achieved, corresponds strictly to the sliding distance when the frictional coefficient starts to decrease. It should be stated that in the case of bearing materials intended for application under dry sliding conditions, two aspects are important. Beside the magnitude of the friction coefficient, the second factor is the temperature up to which the polymer exhibits a "technically acceptable" behaviour. The stabilization of linear wear occurred after different distances depending on the type of PP tested. In the case of the PP tested at a sliding velocity of $0.80 \mathrm{~m} \mathrm{~s}^{-1}$, plasticization takes place first for unmodified PP and then for PP impregnated with gear oil, RME, and finally motor oil (Fig. 4a).

For a sliding velocity of $1.00 \mathrm{~m} \mathrm{~s}^{-1}$, the evolution of friction coefficient curves for unmodified PP and PP impregnated with gear oil is similar and the value of friction coefficient is high from the beginning of the test and then stabilizes after a distance of $300 \mathrm{~m}$. Stabilization and thus plasticization of PP impregnated with rapeseed and motor oils take place after a higher sliding distance. However, in contrast to the test performed at a velocity of $0.80 \mathrm{~m} \mathrm{~s}^{-1}$, the PP impregnated with motor oil stabilizes first, followed by the PP impregnated with RME. Impregnated specimens still show a lower value of maximum friction coefficient (12-19 \%) in comparison to unmodified PP (Fig. 3). By analysing the diagrams of friction coefficient in function of sliding distance it was noticed that impregnation of PP with oils improved the conditions of friction in contrast to the dry friction that occurred during the wearing of the unmodified PP. This is highly visible, especially for the specimens tested at low velocity with a decrease in the friction coefficient value and reduction in friction coefficient variation. 
Fig. 4 Relationship between the sliding distance and the linear wear of the sample under different sliding velocity values
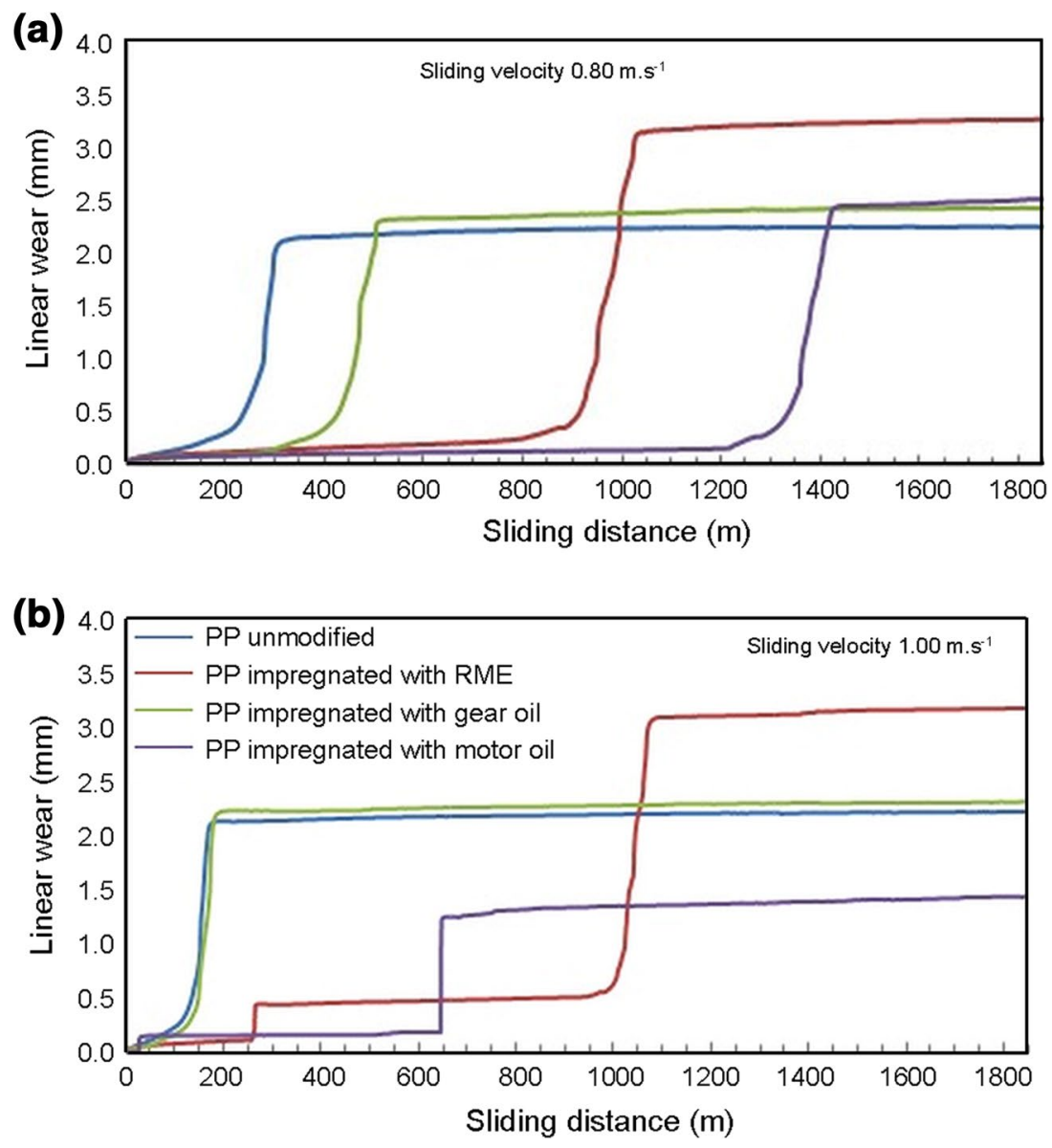

\section{Temperature}

Another factor that strongly influences the contact area between the sliding pair is temperature. Namely, the mechanical properties of PPs are sensitive to change in temperature and liable to chain degradation from exposure to heat. The shape of temperature curves (Fig. 5) obtained during the two-body tribological test corresponds closely to the shape of curves of friction coefficient. In general, the overall temperature of the samples' coefficient increases when the friction coefficient bearing speed increases.

For low sliding velocity values $(0.13,0.26$, and $0.44 \mathrm{~m} \mathrm{~s}^{-1}$ ), the highest measured operating temperatures (Fig. 5a-c) correspond to the unmodified PP and rise to the value of $45^{\circ} \mathrm{C}$. The lower value of operating temperature corresponds to the impregnated PPs. For a sliding velocity value of $0.44 \mathrm{~m} \mathrm{~s}^{-1}$, the PP impregnated with ester-based oil showed the lowest value of temperature, while the PP impregnated with mineral motor oil presented temperatures between those of the PP impregnated with gear and RME oil (Fig. 5c). The temperature rises slightly with distance travelled and its variation is very small for all samples. Higher sliding velocity and consequently higher friction coefficient generate higher temperatures of the operating bearings (Fig. 5d-f). For unmodified PP at a sliding velocity of $0.62 \mathrm{~m} \mathrm{~s}^{-1}$ the temperature rises to the value of $53{ }^{\circ} \mathrm{C}$ after a distance of $450 \mathrm{~m}$, then stabilizes for a while, and drops slightly to the value of $43{ }^{\circ} \mathrm{C}$ (Fig. $5 \mathrm{~d}$ ). The lowest value of temperature still corresponds to the PP impregnated with motor oil; however a value not much higher was noted for the PP impregnated with gear oil. While the temperature curves for the PP impregnated with gear and motor oil rise slightly, the temperature curves of the PP impregnated with RME oil rise sharply, which corresponds to the significant rise of friction coefficient value after a distance of about $1000 \mathrm{~m}$. The value of the temperature of the PP impregnated with RME oil changes by about $62 \%$ from the beginning to the end of the test.

For higher values of sliding velocity, namely 0.80 and $1.00 \mathrm{~m} \mathrm{~s}^{-1}$, the shape of the temperature curves changes significantly and strictly corresponds to the shape of the friction coefficient curves. In the case of PP tested at a sliding velocity of $0.80 \mathrm{~m} \mathrm{~s}^{-1}$ (Fig. 5e), the maximum temperature value is achieved first by unmodified PP and then by the PP impregnated with gear oil, RME, and finally motor oil, which corresponds to the plasticization time (Fig. 5e) of these tested specimens. For a sliding velocity of $1.00 \mathrm{~m} \mathrm{~s}^{-1}$ (Fig. 5f), the evolution of the 

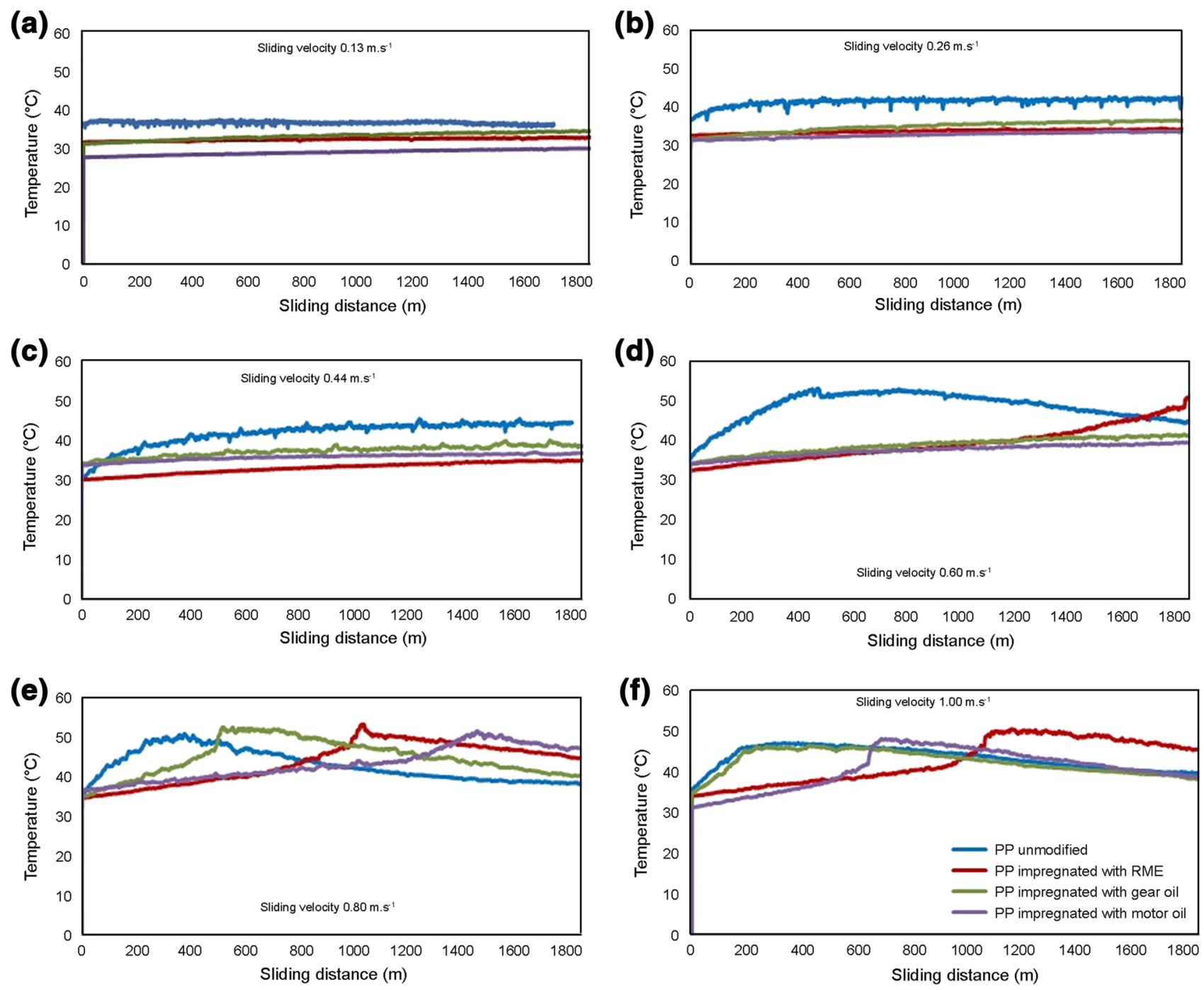

Fig. 5 Relationship between the sliding distance and the temperature of the sample under different sliding velocity values

temperature curves of all tested samples is also similar to the evolution of the friction coefficient curves (Fig. 5f). The maximum value of temperature was achieved first by unmodified PP and the PP impregnated with gear oil, then by the PP impregnated with motor oil, and finally by the PP impregnated with RME oil. At a sliding velocity of $1.00 \mathrm{~m} \mathrm{~s}^{-1}$ the maximum of the friction coefficient and the operating temperature of the PP impregnated with motor oil were achieved after distances of 550 and $700 \mathrm{~m}$, while the corresponding values for the PP impregnated with rapeseed oil were 1000 and $1100 \mathrm{~m}$, respectively. The delay in achieving the maximum value between friction coefficient and temperature was probably due to the fact that the temperature of the overall specimen (not in the contact area) was measured and also the fact that polymers are characterized by low thermal conductivity. However, PP melts at $T=150{ }^{\circ} \mathrm{C}$, which undoubtedly limits its applicability at higher rates of frictional energy production, but the temperature generated at the contact surfaces due to friction is enough to melt the contact surface of the polymer. The temperature at which heat wear starts depends on the type of polymer and is generally lower than the temperature of heat resistance. The scale which is usually used is Martens, ASTM, or Vicat and the edge of the scale is reached, after which an immediate sharp decline in the mechanical properties of the material starts. For PP it is $40-50{ }^{\circ} \mathrm{C}$ according to ASTM [25]. After achieving the maximum, the temperature curves drop similarly to the curves of friction coefficient. The drop in the temperature value can be caused by stopping of the friction process. In the case of unmodified PP, a further reduction in friction coefficient takes place only at temperatures over $42{ }^{\circ} \mathrm{C}$, while in the case of modified PP it takes place at a temperature of about $50{ }^{\circ} \mathrm{C}$. Modification 
Fig. 6 Effect of sliding velocity value on: a linear wear, and $\mathbf{b}$ absolute mass consumption

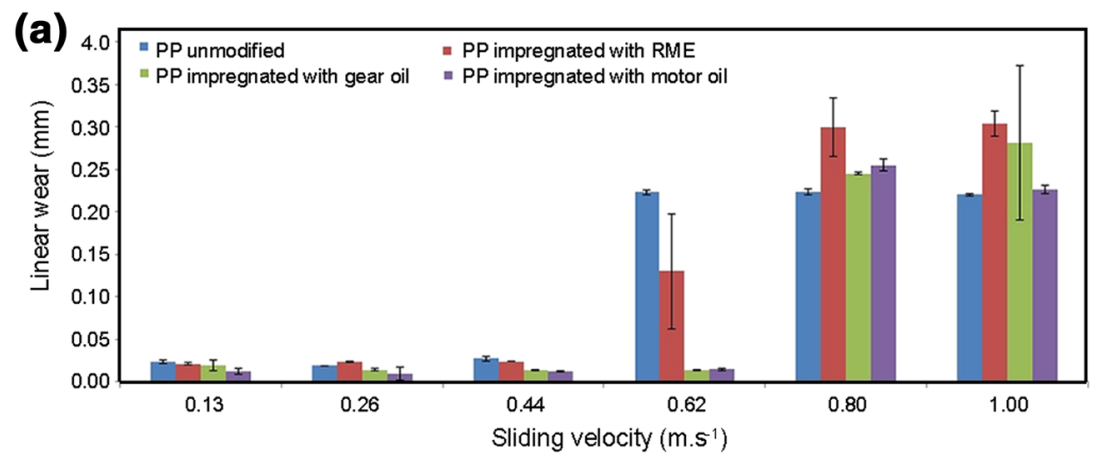

(b)

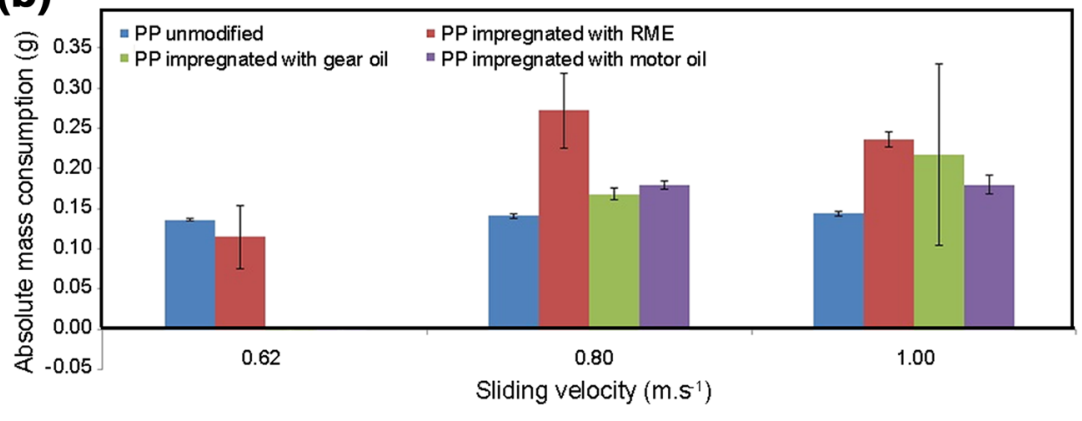

also delays the rise of temperature value that causes the plasticization of the material.

\section{Wear and mass consumption}

The wear rate is high at a high $p v$ parameter ( $p$-contact pressure, $v$-sliding speed) [26]. The wear process is controlled to a greater extent by material transfer, which is a very characteristic phenomenon in polymeric contacts and plays the most important role in friction and wear processes in polymeric tribosystems [26]. The linear wear values and values of absolute mass consumption of the tested components are shown in Fig. 6a, b, respectively. For low values of sliding velocity, namely $0.13,0.26$, and $0.44 \mathrm{~m} \mathrm{~s}^{-1}$, linear wear and thereby absolute mass consumption were low for all specimens. It should also be noted that in the case of absolute mass consumption for sliding velocity values of $0.13,0.26$ and $0.44 \mathrm{~m} \mathrm{~s}^{-1}$, all specimens showed a mass consumption of about $0.001 \mathrm{~g}$, which is not shown in the diagram. A similar value was also noted for the PP impregnated with mineral oil at the test velocity of $0.62 \mathrm{~m} \mathrm{~s}^{-1}$. The wear of the components increases with increasing sliding velocity. Under the test conditions of sliding velocity values of 0.80 and $1.00 \mathrm{~m} \mathrm{~s}^{-1}$, all components reached a high value of relative mass consumption, which was caused by a significant linear wear of the components. Significant wear was observed in the case of unmodified PP even during the test at a sliding velocity of $0.62 \mathrm{~m} \mathrm{~s}^{-1}$. For unmodified PP, the variation of wear was nonlinear, increasing dramatically up to a sliding velocity of $0.62 \mathrm{~m} \mathrm{~s}^{-1}$ and then stabilizing even when sliding velocity increased. The highest wear at sliding velocity values of 0.80 and $1.00 \mathrm{~m} \mathrm{~s}^{-1}$ was noted for the PP impregnated with ester base oil, whose wear was 26 and $38 \%$ higher, respectively, than that of unmodified PP. In contrast to the rest of the specimens, those made of PP impregnated with mineral oils were characterized by lower values of linear wear and absolute mass consumption during the test at sliding velocities of 0.80 and $1.00 \mathrm{~m} \mathrm{~s}^{-1}$. The reduction of the wear provided by this mineral lubricant film was especially visible at a linear velocity of $0.62 \mathrm{~m} \mathrm{~s}^{-1}$. For sliding velocities of 0.80 and $1.00 \mathrm{~m} \mathrm{~s}^{-1}$, even though the wear of these specimens was much lower than that of the PP impregnated with rapeseed oil, it was still higher than that of unmodified PP. The high value of the wear of PP impregnated with RME oil may be due to the fact that even when though the melting temperature of this specimen was reached at the sliding interface, the friction process did not stop.

\section{Wear surfaces}

Figure 7 shows the surface conditions of the analysed samples after the laboratory wear test. Observation of the wear surfaces confirmed the previous conclusion that the unmodified PP was less suitable than impregnated PP for use under conditions of dry running against steel in air. Examination of the worn surfaces using scanning electron microscopy (SEM) made it possible to identify the occurrence of wear mechanisms (Fig. 8). The wear mechanism 


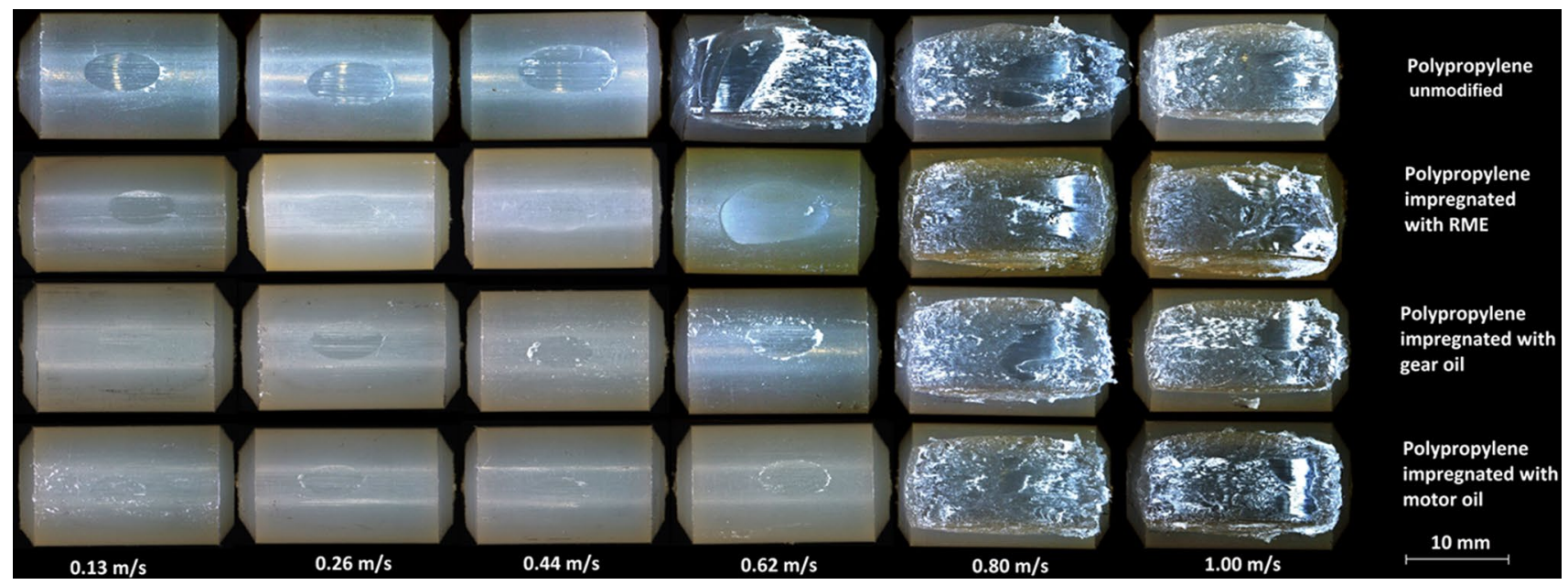

Fig. 7 The effect of sliding velocity value on worn surfaces of tested polypropylene specimens
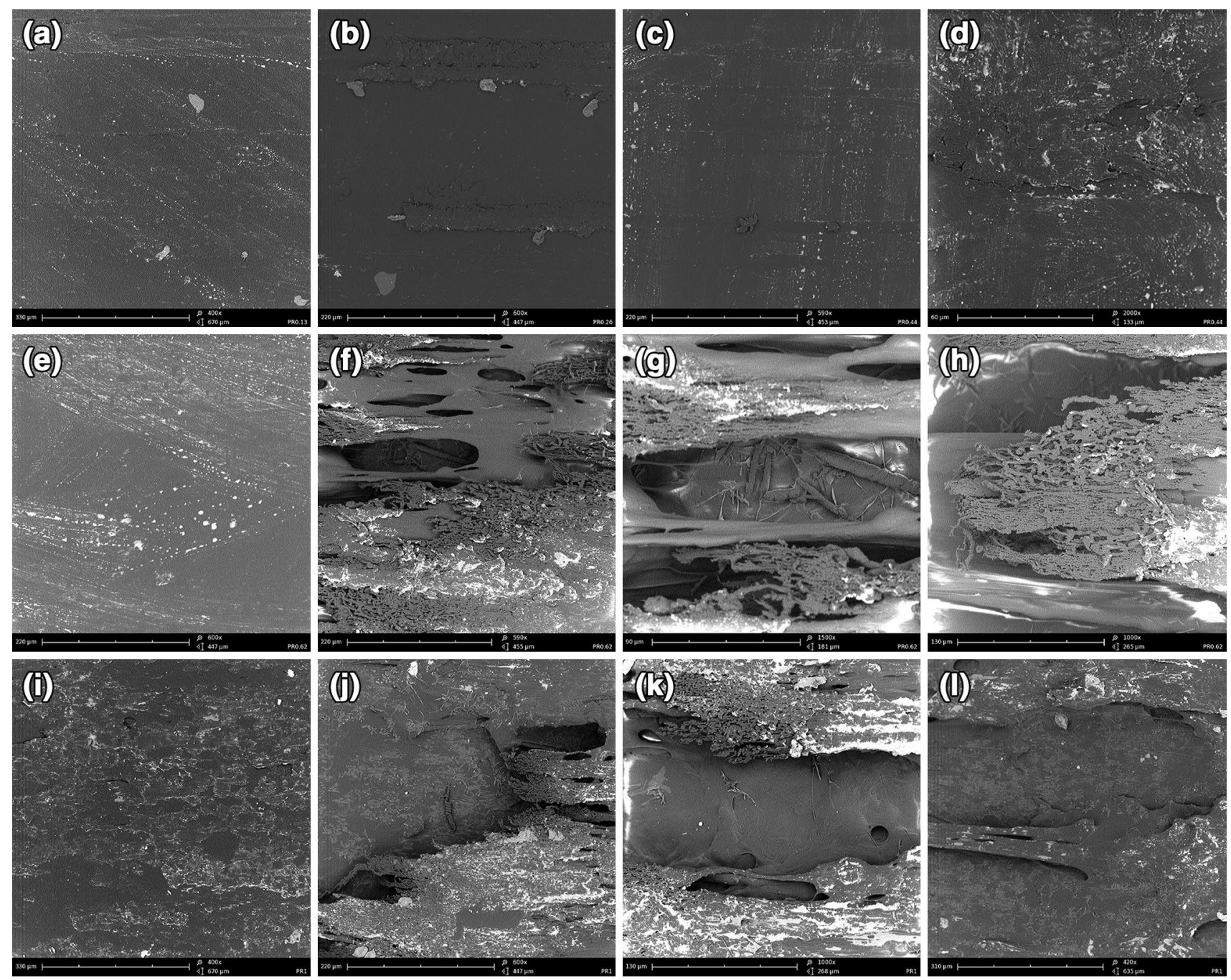

Fig. 8 The effect of the sliding velocity value on worn surfaces of the investigated unmodified polypropylene in the SEM for sliding velocities of: a $0.13 \mathrm{~m} \mathrm{~s}^{-1}$; b $0.44 \mathrm{~m} \mathrm{~s}^{-1} ; \mathbf{c} 0.44 \mathrm{~m} \mathrm{~s}^{-1}$; d $0.44 \mathrm{~m} \mathrm{~s}^{-1}$;

e $0.62 \mathrm{~m} \mathrm{~s}^{-1} ; \mathbf{f} 0.62 \mathrm{~m} \mathrm{~s}^{-1} ; \mathbf{g} 0.62 \mathrm{~m} \mathrm{~s}^{-1} ; \mathbf{h ~} 0.62 \mathrm{~m} \mathrm{~s}^{-1} ; \mathbf{i} 1.00 \mathrm{~m} \mathrm{~s}^{-1}$; j $1.00 \mathrm{~m} \mathrm{~s}^{-1} ; \mathbf{k ~} 1.00 \mathrm{~m} \mathrm{~s}^{-1}$; and $\mathbf{l} 1.00 \mathrm{~m} \mathrm{~s}^{-1}$

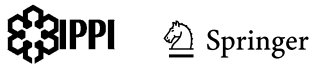


was investigated based on the observation of the worn surface of unmodified PP.

The examination of the wear surface showed differences in the intensity of wear depending on the sliding velocity value and type of PP modification, which was visible especially at a sliding velocity value of $0.62 \mathrm{~m} \mathrm{~s}^{-1}$ when the wear surface of unmodified PP showed significant traces of wear. It can be deduced that the lubrication film located between the metal counter and the PP is effective in decreasing the wear until the sliding velocity value is lower than $0.80 \mathrm{~m} \mathrm{~s}^{-1}$.

The worn surface of the unmodified PP under a sliding velocity of $0.13 \mathrm{~m} \mathrm{~s}^{-1}$ and dry friction was smooth with fine scratches corresponding to the lowest wear rate (Fig. 8a). Some worn debris and spalling cavities that were found in the worn surface showed typical adhesive wear characteristics. The amount of worn debris increased with increasing sliding velocity. After the tribological test at velocities of 0.26 and $0.44 \mathrm{~m} \mathrm{~s}^{-1}$, clear adhesive wear tracks occurred (Fig. 8b-d). The main mechanism for the removal of material was attributed to adhesion. The examination of some grooves showed the presence of wear debris particles and that the material had been partially removed. The worn surface appeared still smooth. When the sliding velocity was low, frictional work was minimally transformed into frictional heat. In contrast, frictional heat was possibly generated at a high sliding velocity and caused local melting and plastic flow of material along the sliding direction. Thermal wear that followed as a result of the dissipation of large amounts of friction energy in the form of heat in the case of unmodified PP started at a sliding velocity between 0.44 and $0.62 \mathrm{~m} \mathrm{~s}^{-1}$ (Fig. 8f-h). The surface wore out more seriously, and further observation of the worn surface was an indication that not only adhesion processes occurred but also fracture took place on the worn surface. It was assumed that the wear surface of the tested PP could be divided into two zones: a smooth zone with adhesion (Fig. 8e) and a zone of ductile deformation and fracture with extensive ductile ploughing of the material and groove formation (Fig. 8f-h). Cracks were not found in the smooth zone, and the surface was clearly softened and smeared with traces of adhesion which was not intensive. The second zone was developed and showed a rough surface topography with a fibrous structure that resembled fractures. On the second zone, small facets or pores, partially deformed plastically, were noticed (Fig. 8f). Examination of some pores showed the presence of additional grooves which were not oriented to the sliding direction (Fig. 8g). Between the facets there were visible bridges. It was also noticeable that most material was predominantly cut and detached from the surface with only some being displaced. With increases in the sliding velocity value, the surface of unmodified PP was not changed dramatically
(Fig. 8i-1). However, on the soft zone there have been higher traces of adhesion wear with some cracks and pit holes (Fig. 8i). Between the fibrous areas the formation of smooth grooves was recognized (Fig. 8k, 1). Pit holes are visible in the groove (Fig. 8k).

It should be added that, even in dramatic wear, the heat wear affects only the polymer and does not affect the counter made of metal. This facilitates the repair process of the friction pair, and usually it is only necessary to replace the element made of polymer.

What is also should be discussed is a known phenomenon of the polymer film, to create a sliding layer of polymer on the surface of a cooperating metal element. This process depends on a number of factors, including the friction process parameters such as sliding speed and pressure unit [27-29] and the condition of the steel surface microgeometry [30-32]. The polymer film may significantly influence the course and dynamics of wear due to replacement of frictional contact polymer-metal with the contact polymerpolymer. It was found that the greater the surface energy was characterized by the polymer, the greater tended the constitution of a stable polymer film which protected the polymer element from direct impacts from metal counter sample of friction.

In the research, due to the earlier impregnation of the tested polymer with the oils, it was assumed that the oils contained in the sample took an active part in the process of friction and wear of tested the tribological pairs. This assumption was confirmed as the coefficient of friction of polymer impregnated at low sliding velocities was much smaller than the friction coefficient of non-impreganted polymer. Also the value of linear wear in the case of impregnated polymer was considered negligible (Fig. 6a).

In the study, the wear of PP impregnated with three different oils in comparison with unmodified PP was investigated using a two-body wear laboratory test. The impregnation of PP clearly influenced the wear rate of PP and its friction coefficient. The research confirmed the data available in the literature showing that the two mechanisms contributing to the friction force between a polymer and steel are adhesion and deformation of the softest material [2, 33]. However, at the high sliding velocity, when a higher temperature was generated, the predominant mechanism of wear was thermal wear, which was confirmed by observation of the worn surface. With this type of wear, spreading or even gluing of the rubbing surfaces often occurred, which led to catastrophic wear [13]. The thermal wear in the case of unmodified PP took place at sliding velocity between 0.44 and $0.62 \mathrm{~m} \mathrm{~s}^{-1}$ while in the case of impregnated PPs it took place at sliding velocity between 0.62 and $0.80 \mathrm{~m} \mathrm{~s}^{-1}$. Thus, one of the advantages of the impregnation of PPs has been the possibility of using them under higher loads. However, impregnated PPs did not show any 
advantage over unmodified PPs in terms of wear rate at the higher sliding velocity values. This phenomenon can be explained by the decrease in oil viscosity with increasing operating temperature [34]. For example Couronné et al. [35] and Cousseau et al. [36] reported that ester-based greases thickened with lithium generated significant lubricant starvation which this type of grease displayed a high flow index.

Also, the evolution of the frictional coefficient value was confirmed by the previous observation. Namely, when the polymer melts, its friction tends to decrease according to a mechanism of "thermal control of friction" [24]. This phenomenon was additionally supported by Quagliny et al. [12]. Quagliny et al. noticed that when the melting temperature of the polymer was reached, the generated heat melted additional polymer rather than causing a rise in the temperature of the already molten polymer. In accordance with the model of limiting frictional heat that was shown in the study [24], the friction coefficient rose until a maximum value was achieved. At this point the friction coefficient determined by the "thermal control model" equalled the friction coefficient dictated by "solid state friction". After reaching its maximum value, the friction coefficient declined to a low level. Observation of the worn surface after friction at the melting temperature showed the presence of two zones: a smooth zone with adhesion and a zone of ductile deformation and fracture. The authors of the investigation [7] clearly showed that softening and smearing were also considered to occur in polyamide 66 at a high sliding velocity. Kukureka et al. [37] also reported that, at higher temperature, softening and smearing of surface occurred in the case of pure nylon 66. An increase in temperature also led to a gradual decrease in the modulus of elasticity and shear strength, which led to a deeper indentation of the steel asperities into the polymer [38, 39].

As mentioned, the wear rate was high at a high $p v$ parameter ( $p$-contact pressure, $v$-sliding speed) [26]. This research [26] also showed a strong dependence between the wear, friction torque, and sliding velocity. At a low sliding velocity value the evolution of the curves of friction coefficient was similar for all tested specimens and the highest value of the friction coefficient was noted for unmodified PP. The existence of lubricant decreased the frictional coefficient value by about $60-70 \%$. At higher sliding velocity the temperature generated at the contact surfaces due to friction was sufficient to melt the contact surface of the polymer, which increased the transfer to the steel surface by adhesion. However, at higher sliding velocity, the wear of PPs impregnated with RME was significantly higher than that of the rest of the specimens.
Despite some uncertainties in the assessment of wear resistance of the tested PPs, it can be considered that the most important finding of this investigation was that impregnation of PPs improved their tribological properties at a low value of load represented by the sliding velocity. Impregnation also moved the thermal wear into higher sliding velocity values and caused better resistance of the PPs to melting and plastic flow. According to these researches it could be concluded that impregnation of PPs even with inexpensive RME oil can give some benefits during their use in low-load frictional pairs under dry-friction conditions.

\section{Conclusion}

1. The laboratory test was used to evaluate two-body wear of PP impregnated with ester-based oil and two mineral oils in comparison to the wear of unmodified PP. The impregnation of the PP clearly influenced its wear rate and friction coefficient. The existence of lubricant decreased the frictional coefficient value by about $12-76 \%$ and displaced the thermal wear to higher sliding velocity values as compared to the unmodified PP, in particular at low sliding velocities of $0.13-0.44 \mathrm{~m} \mathrm{~s}^{-1}$. The greatest reduction in the value of maximum friction coefficient was noted for the PP impregnated with motor oil at a sliding velocity of $0.44 \mathrm{~m} \mathrm{~s}^{-1}$. At low sliding velocity, the friction coefficient variation was very low in the case of the PP impregnated with gear and motor oils, which may reduce the vibration.

2. Sliding velocity values that generated operational heat had a significant effect on the frictional coefficient, linear wear, and absolute mass consumption of the tested PPs. Under a low value of sliding velocity, the adhesion was the predominant mechanism in removal of material. With increasing sliding velocity, besides adhesion, the thermal wear played a greater role in the wear of PPs.

3. The shape of the temperature curves obtained during the two-body tribological test corresponded closely to the shape of curves of friction coefficient. Analysis of frictional coefficient curves showed that under high sliding velocity the frictional coefficient value rose, stabilized after achieving a maximum, and then dropped dramatically.

4. Observation of the worn surface indicated that thermal wear caused melting of the material and thereby two zones could be observed on the worn surface: a smooth zone with adhesion and a zone of ductile deformation and fracture with extensive ductile ploughing of the material and groove formation. 
Open Access This article is distributed under the terms of the Creative Commons Attribution 4.0 International License (http://creativecommons.org/licenses/by/4.0/), which permits unrestricted use, distribution, and reproduction in any medium, provided you give appropriate credit to the original author(s) and the source, provide a link to the Creative Commons license, and indicate if changes were made.

\section{References}

1. Rapoport L, Leshchinsky V, Lvovsky M, Lapsker I, Volovik Yu, Feldman Y, Popovitz-Biro R, Tenne R (2003) Superior tribological properties of powder materials with solid lubricant nanoparticles. Wear 255:794-800

2. Bekhet NE (1999) Tribological behaviour of drawn polypropylene. Wear 236:55-61

3. Lawrowski Z (2007) Polymers in the construction of serviceless sliding bearings. Arch Civ Mech Eng 4:139-150

4. Nunez EE, Polycarpou AA (2015) The effect of surface roughness on the transfer of polymer films under unlubricated testing conditions. Wear 326-327:74-83

5. Stachowiak GW, Batchelor AW (2005) Engineering tribology. Butteworth-Heinemann, Melbourne

6. Unlu BS, Atik E, Koksal S (2009) Tribological properties of polymer-based journal bearings. Mater Des 30:2618-2622

7. Shibata K, Yamaguchi T, Hokkirigawa K (2014) Tribological behavior of polyamide 66/rice bran ceramics and polyamide $66 /$ glass bead composites. Wear 317:1-7

8. Unal H, Mimaroglu A, Kadioglu U, Ekiz H (2004) Sliding friction and wear behaviour of polytetrafluoroethylene and its composites under dry conditions. Mater Des 25:239-245

9. Jia X, Ling R (2007) Two-body free-abrasive wear of polyethylene, nylon1010, epoxy and polyurethane coatings. Tribol Int 40:1276-1283

10. Jia BB, Li TS, Liu XJ, Cong PH (2007) Tribological behaviors of several polymer-polymer sliding combinations under dry friction and oil-lubricated conditions. Wear 262:1353-1359

11. Unlu BS, Atik E, Yilmaz S (2009) Tribological behaviors of polymer based journal bearings manufactured from particle reinforced bakelite composites. Mater Des 30:3896-3899

12. Quaglini V, Dubini P, Ferroni D, Poggi C (2009) Influence of counterface roughness on friction properties of engineering plastics for bearing applications. Mater Des 30:1650-1658

13. Wieleba W (2007) The mechanism of tribological wear of thermoplastic materials. Arch Civ Mech Eng 7:185-199

14. Myshkin NK, Petrokovets MI (2004) Mechanical behavior of plastics: surface properties and tribology. In: Totten GE, Liang $\mathrm{H}$ (eds) Mechanical tribology: materials, characterization, and applications, part one. Marcel Dekker Inc, New York

15. Bowden EP, Tabor DT (1964) Friction and lubrication of solids. Clarendon Press, Oxford

16. Bely VA, Sviridenok AI, Petrokovets MI, Savkin VG (2003) Friction and wear in polymer-based materials. Pergamon Press, Oxford

17. Quaglini V, Dubini P (2011) Friction of polymers sliding on smooth surfaces. Adv Tribol 2011:178943. doi:10.1155/2011/178943
18. Sole BM, Ball A (1996) On the abrasive wear behaviour of mineral-filled polypropylene. Tribol Int 29:457-465

19. http://www.konsil.com.pl/pliki/wlasciwosci_fizyczne_PP.pdf. Accessed 12 Jan 2015

20. http://www.orlenoil.pl/PL/NaszaOferta/Produkty/Strony/ HIPOL_GL-4_80W-90.aspx. Accessed 12 Jan 2015

21. http://www.sklep-grene.pl/images/1/1074/1074 140105_PL_ Karta_charakterystyki.pdf. Accessed 12 Jan 2015

22. Koniuszy A, Podkowa M (2006) Device for testing of lubricating properties of lubricants, US Patent 207802

23. Bekhet NE, Naga SA (1992) An assessment of the frictional and wear behaviour of polyethylene steel couple. In: EGTRIB-92, the 3rd conference of the Egyptian society of tribology, 19-20 Dec, pp 41-53

24. McC. Ettles CM (1987) Polymer and elastomer friction in the thermal control regime. ASLE Trans 30:149-159

25. Janecki J (1982) Zużycie części samochodowych wykonanych z tworzyw sztucznych. Wyd. Komunikacji i Łączności, Warsaw

26. Rymuza Z (2007) Tribology of polymers. Arch Civ Mech Eng $7: 177-184$

27. Franklin SE (2001) Wear experiments with selected engineering polymers and polymer composites under dry reciprocating sliding conditions. Wear 251:1591-1598

28. Unal H, Mimaroglu A (2003) Friction and wear behaviour of unfilled engineering thermoplastics. Mater Des 24:183-187

29. Capanidis D, Ziemiański K (1995) Wpływ wymuszeń zewnętrznych procesu tarcia na kształtowanie warstwy wierzchniej kompozytów polioksymetylenu (POM). TRIBOLOGIA 143:545-552

30. Franklin SE, De Kraker A (2003) Investigation of counterface surface topography effects on the wear and transfer behaviour of a POM-20\% PTFE composite. Wear 255:766-773

31. Wieleba W (2002) The statistical correlation of the coefficient of friction and wear rate of PTFE composites with steel counterface roughness and hardness. Wear 252:719-729

32. Capanidis D (2007) Tribologiczne właściwości kompozytów polioksymetylenu zawierających napełniacz proszkowy PTFE lub PE-UHMW. TRIBOLOGIA 212:105-115

33. Bahadur S, Ludema KC (1971) The viscoelastic nature of the sliding friction of polyethylene, polypropylene and copolymers. Wear 18:109-128

34. Cousseau T, Graca BM, Campos AV, Seabra JH (2012) Influence of grease rheology on thrust ball bearings friction torque. Tribol Int 46:106-113

35. Couronne I, Vergne P, Mazuyer D, Truong-Dinh N, Girodin D (2003) Effects of grease composition and structure on film thickness in rolling contact. Tribol Trans 46:31-36

36. Cousseau T, Graca BM, Campos AV, Seabra JH (2011) Friction torque in grease lubricated thrust ball bearings. Tribol Int 44:523-531

37. Kukureka SN, Hooke CJ, Rao M, Liao P, Chen YK (1999) The effect of fiber reinforcement on the friction and wear of polyamide 66 under dry rolling-sliding contact. Tribol Int 32:107-116

38. Callister WD Jr (2013) Material science and engineering: an introduction. Wiley, New York

39. Ward IM, Sweeney J (2012) Mechanical properties of solid polymers. Wiley, London 